\title{
An Empirical investigation of the Impact of Organizational factors on the Perceived Job Performance of Shop Floor Employees of Large scale Garment Industries in Sri Lanka.
}

\author{
L.D Kalyani \\ Department of Business Management \\ Sabaragamuwa University, Belihuloya
}

\begin{abstract}
Existing literature reveals a gap in the empirical knowledge in respect of organizational factors that impact perceived job performance (PJP) at the large scale garment industries. The present study empirically evaluated four organizational factors that could have impact on the perceived job performance namely Leadership Style, Organization Structure, Organization Culture and Performance Evaluation. The study involved 236 shop floor employees who were selected randomly from 12 large scale garment factories in each province except North and North East provinces in Sri Lanka. Methods such as univariate, bivariate, regression and hypothesis testing were used for data analysis. The results indicated that all the independent variables were positively and significantly correlated to the perceived job performance. However, results regressing the independent variables on the perceived job performance showed that Leadership style, Organization Structure and Performance Evaluation are strong predictors of perceived job performance while organization culture variable is excluded from the model. On the whole, the independent variables accounted for almost $36 \%$ of the variance in the perceived job performance.
\end{abstract}

\section{Introduction}

Perceived job performance is an important factor that contributes to improve the outcomes, behaviour and traits of the employees. It helps to improve the productivity of the organization.

Performance means both behaviour and result. Behaviour emanates from the performer and transforms performance from abstraction to action. Not just the instrument for result, behaviours is also outcomes in their rights the product of mental and physical effort applied to task and can be judged apart from the result (Armstrong , 2000). (Bates and Holton ,1995) have pointed out that performance is a multidimensional construct, the measurement of which varies depending on a variety of factors (Armstrong, 2000). A more comprehensive view of performance is achieved if it is defined as embracing both behaviour and outcomes (Armstrong, 2000).

There are theoretical explantions or arguments (Mullians 1989, Kanungo \& Mendonca 1994, S.S Khanka 2000) in respect of effects of Leadership Style, Organization Structure, Organization Culture and Performance Evaluation on perceived job performance. It seems that there is a gap between the empirical knowledge available about the impact of leadership style, organization culture, organization structure and performance evaluation on perceived job performance of shop floor employees in large sale garment industries in Sri Lanka. Organization Behaviour researchers have to date conducted only a limited number of researches on perceived job performance related to organizational factors. Empirically, performance had been tested as dependent variables with many independent variables and studies P.S Aluthwatte (unpublished,2002), 
Fonseka A.F. (2000), Jayawardana A.K.L (1992) have been done on perceived job performance in Sri Lanka. But they have focused on various personal factors that affect perceived job performance and their studies have no direct link with this study.

Specifically, the following research problems were addressed.

1. Do Leadership Style, Organization Culture, Organization Structure and Performance Evaluation impact on perceived job performance of shop floor employees of large scale garment industries in Sri Lanka.

2. What is the simultaneous effect of these factors on perceived job performance in shop floor employees of large scale garment industries in Sri Lanka.

3. Which organizational factor affects most the perceived job performance of shop floor employees in the large scale garment industries?

For this study, the term perceived job performance is used. The working definition of perceived job performance is the outcomes of work that one thinks the society and the organization expect from him.

There are various types of employees such as management employees, clerical and shop floor employees engaged in the garment industry. Also garment industry can be divided as small, medium and large scale. Only shop floor employees of large scale garment industries were considered for the study. Shop floor employees included machine operators, cutters and helpers.

There are three aspects of the working definition of perceived job performance. They are working outcomes, behaviour and traits of the employees.

\section{Research Model}

Leadership Style refers to the four styles of leaders such as Benevolent, Autocratic, Participative and Democratic. Likert 1961 developed this approach from many years of work by a team at the University of Michigan. Leadership styles is the way in which the function of leaders is carried out, the way in which the manager typically behaves towards members of the group (Mullians 1996). Researchers such as Blake, Mouton and Mc Conse and Mc Gregor have argued that there is 'one best style of leadership, a style that maximizes productivity and satisfaction, growth and development in all situations (Jacques, 1990). Despite some studies that dispute the claim that leadership makes a difference, there is plenty of evidence that leadership can impact performance (Mullins, 1996). In a field study, data were collected from first line managers and from two managers and first line supervisors. The purpose of this research was to assess the direction of causal influence in relationship between leader and follower variables. The result strongly suggested that leader consideration behaviour caused subordinates' satisfaction and that follower performance caused changes in the leader's emphasis on both considerations and the structuring of behaviour performance relationship (Mullins, 1996). Jucius and others (1973) are of the view that it is the drive force of leadership that galvanizes a firm and its people in to materializing the expected results (Mullins, 1996). Hence these arguments lead to the following hypotheses:

$\mathrm{H}_{1}$ : Leadership style of supervisors of Garment industry is positively related to shop floor employees' job performance. 
Organization structure displays the system of task and authority relationship that control how employees use resources to achieve the organizational goals. The evidence generally indicates that work specialization contributes to higher employee productivity but at the price of reduced job satisfaction (Robinson, 2000). Some organization structure is necessary to make possible the effective performance of key activities and to support the efforts of staff (Griffin, 1996). The structure of an organization affects not only the productivity and the efficiency of the economy but also the morale and job satisfaction of the work force. Therefore the Structure should be designed in such a way to encourage the willing participation of members of the organization and effective organizational performance (Mullins, 1999). According to Drucker (1989) a good organization structure does not by itself produce good performance. But a poor organization structure makes good performance impossible, no matter how good the individual manager may be. Improved organization structure will therefore always improve performance. Argyris C. (1964) claims that the formal bureaucratic organization restricts individual growth, self-fulfillment and, the psychological health of a person, causes a feeling of failure, frustration, and conflict. Argyris argues that the organization should provide a more "authentic" relationship for its members. Ford demonstrated that work can be performed more efficiently if employees are allowed to specialize (Robinsion, 2000). According to Stephen Robinson (1989), it may be claimed that the extent to which an organization structure reduces ambiguity for an employee and clarifies problems such as "What am I supposed to do"?, "How am I supposed to do it", "Whom do I report to", "Whom I go to if I have a problem?", shapes their attitudes and facilitates and motivates employees to higher levels of performance. It is difficult to assert categorically the positive effect of organization structure on performance. This is so because there are conflicting findings about the relationship between structural variables like span of control, subunit size, specialization, centralization vs. decentralization and employee performance. Some studies have found positive effects and some have found negative effects (K. Aswathappa, 2000). (Stephen P. Robbins, 2000) has indicted that strategy, size, technology, and environment determine the type of structure an organization will have. Here, the structure is designed around one of the two models: mechanistic or organic. The specific effects of structure designs on performance and satisfaction are moderated by employees' individual preferences and culture norms. Based on these arguments, the second hypothesis for the study is as follows;

$\mathrm{H}_{2}$ : Organization structure of Garment industry is positively related to shop floor employees' job performance.

Organization culture is defined as a part of an organizational life that influences the behaviour, attitudes and overall effectiveness of employees. More recent writers have repeated the assumption that 'organizational culture impacts significantly on an organization, its employees' behaviour and motivation and, ultimately, on organizational financial performance' (Holmes \& Marsden, 1996:26). However, despite both the longevity and currency of claims about the association between organizational culture and desired organizational and individual outcomes, little empirical research has been conducted to provide evidence for the claims (Chee W Chow, Graeme L Harrison, Anne Wu, 2001). Organization culture has assumed considerable importance nowadays because of its impact on employee performance and satisfaction (K. Aswathappa, 2000). Robert Kreitner and Angelo Kinicki (1995) indicated how organizational culture 
affects performance and satisfaction. They indicated organization culture as an intervening variable. Employees form an overall subjective perception of the organization based on such factors as the degree of risk tolerance, team emphasis, and support of people. This overall perception then affects employee performance and satisfaction, with the impact being greater for stronger culture. Thus, the third hypothesis is

$\mathrm{H}_{3}$ : Organization culture of the garment industry is positively related to shop floor employees' job performance.

Performance evaluation refers to the judgmental evaluation of a job holder's traits, behaviour and outcomes (Hopwood, 1972, Otley, 1978, Bronel, 1982, Hirst, 1983, Govindorajan, 1989, Brownell and Hirst, 1986, Brownell \& Dunk, 1991). Prior research results suggested that the superior's evaluative style may influence subordinate's job performance (Chong M Lau, 2004). Employee job performance is an important issue for all organizations (Mathis and Jackson, 2000). It is concerned with controlling and development of employees' job performance.

Performance evaluation serves many purposes. According to Prasad and Bennerjee's (1994) prescription, the objectives of the annual or periodical appraisal should be, to evaluate the results and plan for better performance, to understand the gaps in knowledge skills and training needs, to identify men with potential to man higher positions in the future (Opatha,2000). (Furtwongler, 2000) describes five goals of performance evaluation such as performance improvement, employee development, employee satisfaction, compensation, decisions and communication skill (Opatha, 2000). Based on the available literature, the following is the fourth Hypothesis for the study

$\mathrm{H}_{4}$ : Performance Evaluation system of Garment industry is positively related to shop floor employees' job performance.

Combined influence of the above variables on the PJP refers to simultaneous effect of the above four variables on PJP. Leadership Style, Organization Structure, Organization Culture and Performance Evaluation were hypothesised as independent variables that positively relate to the PJP.

The following figure indicates the Conceptual Diagram of the research

\section{Figure 1}

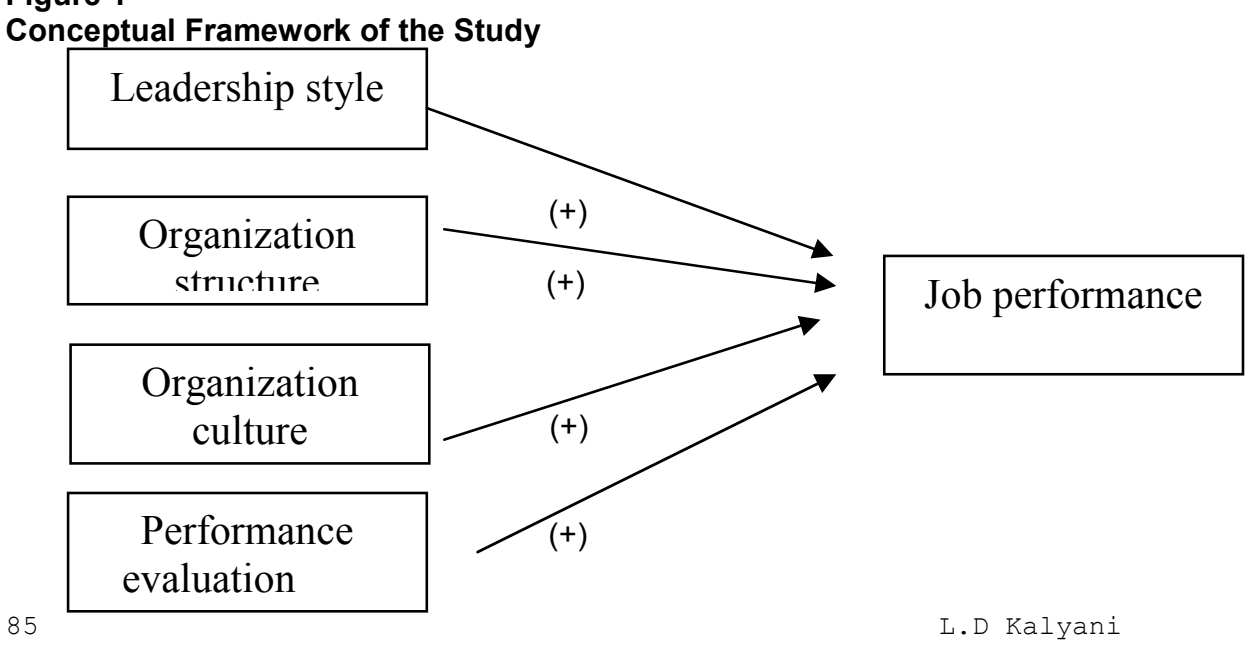




\section{Method}

\section{Study setting, Design \& Sampling}

Researchers have found multiple factors that influence perceived job performance (Armstrong 2000). Thus, the researcher was interested in explaining the effects of four factors (leadership style, organization structure, organization culture and performance evaluation) on perceived job performance rather than establishing definite cause ${ }^{\circledR}$ effect relationship. Therefore, the type of investigation of this study was correlation.

The survey was carried out in 12 large scale garment factories in Sri Lanka. Unit of analysis was at individual level of the shop floor level employees. There were approximately 10000 shop floor employees in all 12 factories. A sample size of 264 shop floor employees 22 from each firm was selected for the study. The questionnaire for the shop floor employees was distributed in Sinhala language according to simple random sampling. It was possible to collect 236 questionnaires from 12 large scale garment industries.

\section{Measures}

PJP: - The perceived degree of job performance of an employee was operationalised in to three dimension i.e., Task performance, Social Behaviour and Performance Traits(Cox T. Jr. \& Nkomo S.M 1986, Borman ,1990, A.F. Fonseka 2000). Indicators/ elements used to measure these dimensions with relevant sources from which they were adopted are (1) Task performance: plan for target achievement, Target Achievement, achieve all organizational goals, optimize the use of resources under my care (Cox.T.Jr. \& Nkomo S.M 1986, A.F. Fonseka 2000) (2) Social Behaviour: relation with others, always helpful to others (Cox.T.Jr. \& Nkomo S.M 1986, A.F. Fonseka 2000). (3) Performance Traits: Maximum effort extension, work in methodical way (Cox, A.F Fonseka). An instrument containing 8 questions items that tap the dimensions and elements of PJP was developed and two sample statements are: "I plan my work to achieve the target ahead", I have good relationship with my peers. The responses to the questions were elicited on a 5 point Likert type scales of strongly agree, agree, neither agree nor disagree, disagree. Weightages or values of $5,4,3,2$ and 1 were given to these, taking the direction of the question items in to account.

Leadership Style: This independent variable was measured by using a self developed questionnaire. They included Benevolent, Autocratic, Participative and Democratic. The instrument contains 7 statements and the respondents were asked to indicate their degree of non acceptance or acceptance on a 5 point scale. The sample questions used are; (1) I feel that my supervisors communicate the goal clearly. (2) I feel that my supervisors enhance workers' self esteem and self confidence.

Organization Structure: The variable was measured by using an instrument developed by self. They included Hierarchy of Authority, Division of labour, Span control and Line and Staff position. These dimensions were measured by using 7 questions from which responses were elicited on a 5 point likert scale ranging 
from strongly disagree to strongly agree. Weightages of 1, 2, 3, 4 and 5 were given to responses considering the direction of the question items. Two sample questions are used: (1) I feel that my garment factory structure is highly job specialized. (2) I feel that my garment factory structure has a long chain of command.

Organization culture: organization culture was operationalized in to six dimensions based on the writing of John Martin, 1998 \& Schein 2000 and they included organization climate, norms, values, rules, regulations and philosophy. Twelve question items were used to measure the organization culture. The respondents were asked to indicate their degree of agreement or disagreement about the organization culture according to a 5 point scale.(1= strongly disagree, 5 = Strongly agree) Two sample items are used: (1) I feel that my factory provides essentials such as drinking water, sanitary facilities to serve our purpose. (2) I feel that my factory treats all workers alike.

Performance Evaluation: The variable was measured with self developed instrument. They included Result, behaviour and Traits. These dimensions were measured using 5 questions from which responses were elicited on a 5 point likert scale ranging from strongly disagree to strongly agree. Weightages of 1,2 , 3,4 and 5 were given to responses, considering the direction of the question items. The two sample questions used are: (1). I feel that my factory expects me to perform my duties honestly. (2). I feel that my factory expects me to attend to the work at the right time in the right way.

\section{Reliability and validity of the instrument}

The Chonhbach's coefficient alpha value was measured to check whether each questionnaire measures the variable reliably (Watsh,1995). Chonhbach's alpha were 0.8814 for leadership style, .6528 for the organization structure, 0.8838 for the organization culture and 0.7971 for the performance evaluation. Conceptualization of both dependent variable and independent variable was based on models used in researches published previously. This method was used to increase the content validity of operationalising the research and to increase comparability.

The correlation analysis supports the hypothesis formulated linking the relationship between the PJP and the independent variables. The acceptance of hypothesis linking the relationship between PJP and the independent variables suggests that instrument possesses adequate construct validity.

\section{Result}

The results of Pearson's coefficient of correlation analysis used to test all the null hypotheses are presented in Table 1. As the bivarial hypotheses are concerned with a positive relationship, one tailed test was used.

Table 1 Pearson correlation Matrix for all variables

\begin{tabular}{|c|l|l|l|l|l|}
\hline No & \multicolumn{1}{|c|}{ Variables } & \multicolumn{1}{c|}{1} & \multicolumn{1}{c|}{2} & 3 & 4 \\
\hline 1 & PJP & 1.0 & & & \\
\hline 2 & Leadership style & $0.409^{* *}$ & 1.0 & & \\
\hline 3 & Organization structure & $0.481^{* *}$ & $.295^{* *}$ & 1.00 & \\
\hline 4 & Organization Culture & $0.461^{* *}$ & $.431^{* *}$ & $.638^{* *}$ & 1.00 \\
\hline 5 & Performance Evaluation & $0.380^{* *}$ & $.232^{* *}$ & $.379^{* *}$ & 1.00 \\
\hline
\end{tabular}


As can be seen in Table 1, all the four variables are correlated over 0.380 . The correlation coefficient of all of the variables were significantly greater than zero, and therefore the null hypotheses propos for these variables were rejected $(P<.01)$. This means that the data support the hypothesised relationship (positive) between each of the variables and PJP.

Multivariate analysis evaluates the simultaneous effects of all the independent variables on the PJP. The second hypothesis of this study is concerned with the aggregate impact of the four variables on PJP. The results of regressing the four independent variables against the dependent variable PJP are shown in Table 2.

Table 2.

\begin{tabular}{|c|c|c|c|c|c|}
\hline $\mathrm{R}$ & $\mathrm{R}$ Square & $\begin{array}{c}\text { Adjusted } \mathrm{R} \\
\text { Square }\end{array}$ & $\begin{array}{c}\text { Std. Error of } \\
\text { the estimate }\end{array}$ & $\mathrm{F}$ & Sig. $\mathrm{F}$ \\
\hline 0.589 & 0.347 & 0.339 & 0.39 & 41.177 & 0.000 \\
\hline
\end{tabular}

The square of the multiple $\mathrm{R}$ is 0.347 indicating that the $35 \%$ of variance in PJP is explained by the four independent variables jointly. The $F$ value is 41.177 , which significantly explains $35 \%$ of the variance in PJP.

A stepwise regression was done in finding out the extent of contribution of each variable to $\mathrm{R}$ square value or the total explanatory power of the regression model. The result of stepwise regression (Table 3) shows that there were three predictor variables that could significantly contribute to the $\mathrm{R}$ square value.

Table 3. Stepwise multiple Regression Analysis: Predictors of PJP

\begin{tabular}{|l|c|c|c|}
\hline \multicolumn{1}{|c|}{ Variable } & $\mathrm{R}^{2}$ & Beta & Sig. $\mathrm{t}$ \\
\hline Organization structure & 0.231 & 0.481 & 8.386 \\
\hline Leadership style & 0.309 & 0.292 & 5.132 \\
\hline Performance Evaluation & 0.347 & 0.209 & 3.684 \\
\hline
\end{tabular}

$\mathrm{R}^{2}=35 \quad$ Adjusted $\mathrm{R}^{2}=0.339 \quad \mathrm{~F}=41.177$

The results of the stepwise multiple regression analysis indicated that organization structure impact the PJP had highest beta value \& contributed about $23 \%\left(R^{2}=.231\right)$ to the variance in PJP. Leadership style of supervisors contributed about $7 \%$ (change in $\mathrm{R}$ square 0.078 and $.038(4 \%)$, respectively. organization culture was not found contributing to the explanatory power suggesting that Organization Structure, Leader ship Style and Performance evaluation explained about $35 \%$ of variation in PJP.

\section{Discussion}

As hypothesized, it was found that the favorable organization structure had more impact on PJP. As the variable was found to be a significant predictor of PJP, a proper organization structure had a high impact in determining the PJP in large scale garment industries in Sri Lanka. The findings empirically confirm the theoretical arguments given by Donalld D white \& David A Bendnar (1988), Henry Ford (1998), Robinsion (2000), Argyric C (1964). They explained that organization structure had an impact on PJP significantly. Further, there appears to be a very little variation in different organization structure. A comparison of 
correlation of coefficient reveals that division of labour does appear to be more strongly correlated to PJP than other dimensions of organization structure. The reason for this type of outcome may be due to using the specialized knowledge and the experience of employees by retaining them in the same position.

A positive and significant relationship was found between leadership style and PJP. Also it was found that leadership style was the strongest predictor of PJP.

The leadership style variable of the sample gives a satisfactory level, $(M=3.93$, S.D.=.63). The leadership styles are to be close to agree than to neither agree nor disagree. Thus, it explains that they have favorable level of leadership style.

The findings empirically support the arguments of David A Waldman \& William D Spongler (1989), Vrom, Yetton and Jago model (1988), Mullians (1989), Lewin, Lippit and White (1977). They explained the importance of leadership style in improving PJP.

The organization culture was found to be positively and significantly related to PJP (with in correlation analysis). This is significant at $0.01 \%$ level $(P<0.0001)$. The regression analysis does not support this clearly. Though organization culture is taken as a predictor to PJP, the influence of this variable on the dependent variable is negligible (This variable was excluded in the regression analysis). This may be because of the effects of other two variables taken together during regression analysis. The findings empirically confirm the theoretical arguments given by Stephen James Heskett (1998) and John E Sheridan (1992). The findings suggest that large scale garment industries attempted to develop an organization culture within their organization in order to enhance PJP.

Performance Evaluation was found to be positively and significantly related to PJP. Further, a comparison of the correlation coefficient reveals that it appears to be less strongly correlated to PJP than the other independent variables. The findings are consistent with the arguments of Mullian (1989), A. H. Locher and K.S. Teel (1988), Robet Kreitner (1995). The study findings are different to those ideas of Robision (2000). He has concluded that traits such as loyalty and initiative may be prized by managers but there is no evidence to support that certain traits will be adequate synonyms for performance in a large cross section of jobs.

From multivariat analysis, out of the four factors, three factors namely Organization Structure, Leadership Style and Performance Evaluations were found to be explanatory factors having significant effect on PJP. The implication of the finding is that if garment industries need to enhance PJP, Organization Structure, Organization Culture, Leadership Style and Performance Evaluation are critical to be considered and various strategies can be applied to enhance PJP. Strategies should focus on improving the present level of variables. Organization structure was found as the strongest predictor of PJP. That reason may be a proper organization structure provides a clear picture to employees and it affects to improve the PJP of the employees.

\section{Conclusion and implication}

It was not possible further for four independent variables to account for $35 \%$ of the variation in PJP. In fact, other variables, which were not considered in this 
study, should be the variable that will account for the unexplained variance in the PJP. The researcher believes that the important independent variable may be the Personal Attitudes (Employee Commitment, Involvement, Satisfaction), Organization Policies and Rewards System. Further research studies are suggested to carry out to find out the effect of these factors on the PJP. In measuring the variable, there are no measurement instruments currently developed. It will be a great barrier to the future researchers.

The study was limited to investigate the impact of Organization Structure, Organization Culture, Leadership Style and Performance Evaluation on the PJP in large scale garment industries. Further investigations in other types of firms and industries may provide additional insight in to the findings of the study. This research was limited to a particular employee segment (only shop floor employees except supervisors).

The findings of this research should be important both on the theoretical level and practical level. The study suggests that the garment industry should pay high attention to improve the organization structure using the most appropriate criteria. The study also suggests that the garment industry should pay more attention to improving division of labour (one dimension of the organization structure). Not only has it been identified as a key factor related to job performance, but it has also been identified as the key source of labour specialization. Leadership Style and Performance Evaluation are also significantly related to job performance. Thus, if the large scale garment industry ignores them altogether, employee job performance may be seriously affected.

Further, this study should draw more attention of future researchers towards this important field. This is an interesting field for research and few researches have been done in Sri Lanka. It is suggested that future studies look deeply into the organization factors impact on PJP. Further, attention should be paid to compare the shop floor employees and non shop floor employees' PJP in future studies. Some researches could be done using different indicators for key variables. This could help to find out whether the analysis is indicator dependent.

\section{References}

Argyris, C. 1964. Integrating the Individual and the Organization, New Delhi: Wiley Publishers.

Armstrong, Michael. 2000. Performance Management, New York: Kogon Page Publishers

Aswathappa, K. 2000. Organizational Behaviour, New Delhi: Himalaya Publishers.

Campbell, J.P. \& Pritchard, R.D. 1976. Motivation Theory in Industrial and Organizational Psychology, Chicago : Rand Mc. Nally Publishers.

Campbell, W. 1990 . Performance Improvement in Public Enterprises Sri Lanka, Journal of Development Administration Vol. 7: 23-28.

Chee, W. Chow, Graeme, L. , McKinnon, J.L. and Wu, A. 2001. Organization Culture: Association with Affective Commitment, Job Satisfaction, Propensity to remain and information sharing in a Chinese Culture context. CIBER Vol. 22: 116.

An Empirical investigation of the Impact... 
Chong, M. L. and Buckland, C. 2003. The Impact of Supervisory Evaluative Style on Managerial Performance. Journal of Management Vol. 12: 1-8.

Cox Jr. T. and Nkomo S.M. 1986. Differential Performance Appraisal Criteria: A Field Study of Blake and White Managers, Group \& Organization Studies. HRM Journal Vol.11 Nos.1-2, 101-119

David. M. \& Spangler. J. 1989. Self Efficiency \& Task Performance, New York: Academic Press.

White, D.D. and. Bednar, D.A. 1986. Organizational Behaviour, New Delhi: Boston, Allyn and Bacon Publishers.

Drucker, P.F. 1989. The practice of Management. Journal of Heinemann Professional

Vol 40: 22-38

Schein, E.H. 1990. Organizational Culture, New york: Thomsan Publishers.

Fonseka A. F. 2000. An Empirical Investigation between Work Attitudes and Perceived Job Performance of Public Sector Engineers in Engineering Culture, Unpublished M.Sc (Mnagement) Thesis, University of Sri Jayawardanapura.

Luthans, F. 2002. Organization Behaviour, London: Irwin McGrewHillPublishers.

Opatha, H.H.D.N.P. 2002. Performance Evaluation Human Resources, Colombo: Published by Author.

Hersey, P. \& Blanchard K. H. 1989. The Management of Organization Behaviour, New Jersey: Prentice Hall Publishers.

Gibson, J.L. , Ivancevicn, J.M. , Donnelly, J.H. 1997. Organizational Behaviour Structure Processes, New Delhi: Irwin McGraw -Hill Publisher

Jayawardana A.K. L. 1992. A study of the Tendency to Participate, PIM Conference on Management Studies, The Emerging Economic Order in Sri Lanka, Unpublished Thesis, Post Graduate Institute of Management in Cooperation with USJ .

Kotter, J.P. and Heskett, J.L. 1992. Corporate Culture and Performance, New York: Free Press Publishers.

Kanungo, Rabindra. 1994. Work Motivation, New Delhi: Sage Publication.

Khanka, S.S. 2000. Organizational Behaviour, New Delhi : S. Chand \& Company Ltd Publishers.

Kreitner R., Kinicki, A. 1995.Organizational Behaviour, New york: Richard D Irwin, INC Publishers.

Lambrinides, T. 2000: Factors affecting performance. Hard Training Magazine Vol $15: 1-5$ 
Lewin , K., Lippitt, R. and White, R.K. 1939: Patterns of Aggressive Behaviour in Experimental Created Social Environment. International Journal of Social Psychology, Vol. 10: 66-78

Likert, R. 1961. New Patterns of Management, New York: McGraw-Hill Publishers

Locher, A.H. and Teel, K.S. 1988: Appraisal Trend. Personal Journal Vol 45: 139-145.

Martin, J. 1998. Organizational Behaviour, New York: Thomson Business press.

Mathieu, J.E. 1990: A test of Subordinates' Achievement and Affiliation Needs as Moderators of a Leader Path Goal Relationship. Journal of Applied Social Psychology Vol 33 : 33-46

Moorhead, Griffin. 1999.Organizational Behaviour, Toronto: Houghton Mifflin Publishers.

Morrehead, G. , Griffin R.W. 1993. Organization Behaviour Managing People and Organizations, Toronto: Houghton Mifflin Publishers.

Mullins, Laurie J. 1996. Management and organization Behaviour, London: Wheeler Publishers.

O'Reilly C.A., Chatman, J. 1991: People and Organization Culture. Academic of Management Journal Vol. 14: 487-516.

Aluthwatte, P.S. 2002. An Empirical Investigation between Work Attitudes; Rewards and Job Performance in the Garment Industry of Sri Lanka, Unpublished M.Sc Thesis, University of Sri Jayawardanapura.

Benet, R. 1991. Organization Behaviour, London: Pitman Publishers.

Kreitner, R. and Kinicki, A. 1995. Organization Behaviour, London: Wheeler Publishers.

Robinsons S.P. 2001. Organizational Behaviour, NewDelhi: Prentice Hall Publishers.

Sheridan J.E. 1992: Organizational Culture and Employee Retention. Academy of Management Journal Vol. 55: 36-56.

Tannenbaum, R and Schmidt, W.H. 1958: How to chose a Leadership Pattern. Harward Business Review Vol. 66: 75-162.

Vroom, V. H. and Jago, A. G. 1988. The New Leadership: Managing Participation in Organization, New Delhi: Prentice -Hall Publishers.

Vroom, V. H. and Yetton, P.W. 1973. Leadership and Decision Making, New York: University of Pittsburgh Press. 